\title{
Effect of acid whey and freeze-dried cranberries on lipid oxidation and fatty acid composition of nitrite-/nitrate-free fermented sausage made from deer meat
}

\author{
Małgorzata Karwowska ${ }^{1, *}$ and Zbigniew J. Dolatowski ${ }^{1}$
}

\footnotetext{
* Corresponding Author: Małgorzata Karwowska Tel: +48-81-4623344, Fax: +48-81-4623345, E-mail: malgorzata.karwowska@up.lublin.pl

' Department of Meat Technology and Food Quality, University of Life Sciences in Lublin, 20-704 Lublin, Poland
}

Submitted Jan 7, 2016; Revised Feb 24, 2016; Accepted Apr 18, 2016
Objective: This study evaluated the effect of acid whey and freeze-dried cranberries on the physicochemical characteristics, lipid oxidation and fatty acid composition of nitritefree fermented sausage made from deer meat and pork fat. Antioxidant interactions between acid whey and cranberry compounds were also explored.

Methods: Four formulations of fermented venison sausage were prepared: F1 (control), F2 (with 5\% liquid acid whey), F3 (with $0.06 \%$ of freeze-dried cranberries), and F4 (with $5 \%$ liquid acid whey and $0.06 \%$ of freeze-dried cranberries). Each sample was analyzed for $\mathrm{pH}$, water activity $\left(\mathrm{a}_{\mathrm{w}}\right)$, heme iron content, 2-thiobarbituric acid reactive substances (TBARS) value and conjugated dienes at the end of the manufacturing process and at 30 and 90 days of refrigerated storage. Fatty acid composition was measured once at the end of the manufacturing process.

Results: At the end of ripening, all samples presented statistically different values for a $\mathrm{pH}$ range of 4.47 to $\mathrm{pH} 4.59$. The sum of the unsaturated fatty acids was higher, while the conjugated diene and the TBARS values were lower in sausages with freeze-dried cranberries as compared to the control sausage. The highest content of heme iron $(21.52 \mathrm{mg} / \mathrm{kg})$ at day 90 was found in the sausage formulation with the addition of freeze-dried cranberries, which suggests that the addition of cranberries stabilized the porphyrin ring of the heme molecule during storage and thereby reduced the release of iron. The use of liquid acid whey in combination with cranberries appears to not be justified in view of the oxidative stability of the obtained products.

Conclusion: The results suggest that the application of freeze-dried cranberries can lower the intensity of oxidative changes during the storage of nitrite-free fermented sausage made from deer meat.

Keywords: Fermented Sausage, Freeze-dried Cranberries, Lipid Oxidation, Fatty Acid Profile

\section{INTRODUCTION}

Over the last few years, consumers have shown a growing interest in new red meat such as game and venison. Consumption of these types of meat is growing in many parts of the world because consumers consider game and venison to be healthier than the meat of farm animals. Venison is lower in calories, muscle fat contents and cholesterol when compared to beef, pork or lamb [1]. It has several other attributes that are attractive to health-conscious consumers, e.g. a favorable fat composition and high levels of minerals [2]. Venison is also characterized by a high content of phospholipids and myoglobin, which makes it susceptible to oxidation [3].

In recent years, several studies have been carried out on the physicochemical characteristics 
and fatty acid composition of deer meat. Red deer meat was found to have a low fat content and a high content of total protein and water-soluble nitrogen in relation to total nitrogen [4]. Quaresma et al. [5] reported that Iberian red deer meat was characterized by a high content of polyunsaturated fatty acids (total PUFAs comprise approximately $30 \%$ of total fatty acids), and particularly rich in 18:2 n-6, 18:3 n-3 and 20:4 n-6. Despite its nutritional value, venison is considered to be difficult to prepare. Therefore, the current trend is to process venison meat. Since the main reason for the growing interest in venison is that the nutritional value of this type of meat is superior to that of farm animals, it is important to process venison without the addition of nitrites and nitrates. In recent years, nitrite's safety to human health has been questioned as nitrite can cause the formation of carcinogenic nitrosamines [6]. One of the primary functions of nitrite is to act against lipid oxidation by the binding of heme and to prevent the release of catalytic iron, the binding of heme and nonheme iron, and the inhibition of catalysis and stabilization of lipids against oxidation [7]. Thus, it is obvious that the manufacture of nitrite-free sausage poses problems to meat processors, including oxidation processes.

Despite the growing interest in products from game meat, comparably few studies have dealt with the quality aspects of meat products from deer [8], and in particular fermented sausages from deer [9]. During the ripening of fermented sausages, different chemical and physicochemical changes take place, among which protein and lipid degradation are the most important and have the greatest effects on the quality traits of the final product [10]. The most practical way to inhibit oxidative deterioration in uncured dry-fermented sausages is to incorporate antioxidants into the product formulation.

A large variety of phenolic compounds from plant materials has been found to exhibit antioxidative activity, but their individual efficiency to protect lipids from oxidation was found to depend on both the structure and concentration of the phenolic compounds [11]. In a study by Lee et al. [12], cranberry phenolics were shown to inhibit hemoglobin-mediated lipid oxidation in cooked pork and raw, mechanically separated turkey. Kathirvel et al. [13] identified flavonol aglycone and quercetin as compounds responsible for lipid oxidation inhibition of an extract prepared from cranberry juice powder in mechanically separated turkey.

The antioxidative effect of whey proteins is mainly associated with beta-lactoglobulin and lactoferrin due to their ability to inactivate prooxidative heme proteins (ferrylmyoglobin) and to bind iron [14]. Thus, the use of whey in the production of venison sausage seems to be justified by the fact that venison has a large amount of heme iron which makes it susceptible to oxidative changes.

In an attempt to investigate the feasibility of using acid whey and cranberries for the production of nitrite and nitrate-free fermented products, this study evaluated the effect of acid whey and freeze-dried cranberries on the lipid oxidation, physicochemical characteristics and fatty acid composition of nitritefree fermented sausage made from deer meat and pork fat. Antioxidant interactions between acid whey and cranberries compounds were also explored.

\section{MATERIALS AND METHODS}

\section{Fermented sausage production}

Approximately $30 \mathrm{~kg}$ of raw meat from deer (Musculus biceps femoris muscle) was sourced from a game meat processing company and $9 \mathrm{~kg}$ of backfat from domestic pigs from a meat cutting plant. The selected animals were from the same age, consisting of three female deer grown under the same condition. The deer (Dama Dama L.) were kept on a deer farm located in eastern Poland in welfare conditions outdoors throughout the year, pasturing on grazing plots in summer and feeding on basic farm fodder in winter (hay-silage from grass, corn, and hay). Raw meat was obtained from deer slaughtered at the age of 18 months of age. The backfat came from the carcasses of Polish Large White purebred fatteners raised and slaughtered at 9 months of age. The muscles and backfat were excised at $48 \mathrm{~h}$ post mortem from carcasses chilled at $2^{\circ} \mathrm{C}$.

Additional ingredients used for the production of sausages in this study included sea salt, acid whey and freeze-dried cranberries. According to the certificate, the sea salt used in the experiment contained $99.74 \%$ sodium chloride and contained no nitrites or nitrates. Liquid acid whey $(94.1 \% \pm 0.95 \%$ moisture content; $\mathrm{pH} 4.60 \pm 0.01$ ) was obtained during traditional cottage cheese production from a dairy processing plant. Commercial freeze-dried cranberries were provided by WPPH Elena (Żelazków, Poland). This cranberry product was chosen since a study performed by Grace et al. [15] indicated that freezedrying did not cause detectable losses of anthocyanins or proanthocyanidins in cranberry fruit.

Four formulations of fermented venison sausage were prepared: F1 (control), F2 (with 5\% liquid acid whey), F3 (with $0.06 \%$ of freeze-dried cranberries), and F4 (with 5\% liquid acid whey and $0.06 \%$ of freeze-dried cranberries). The experimental design and the amounts of relevant ingredients used here are shown in Table 1. The following ingredients, common to all formulations, were also added: $25 \mathrm{~g}$ sea salt and $6 \mathrm{~g}$ glucose per $1 \mathrm{~kg}$ of meat mixture. Cold tap water (5\%) was added to

Table 1. Experimental design and ingredients used ( $\mathrm{g} / \mathrm{kg}$ of product)

\begin{tabular}{lcccc}
\hline \multirow{2}{*}{ Ingredient } & \multicolumn{4}{c}{ Formulations } \\
\cline { 2 - 5 } & F1 & F2 & F3 & F4 \\
\hline Deer meat & 750 & 750 & 750 & 750 \\
Backfat & 169 & 169 & 169 & 169 \\
Liquid acid whey & - & 50 & - & 49.4 \\
Water & 50 & - & 49.6 & - \\
Dry-freeze cranberries & - & - & 0.6 & 0.6 \\
\hline
\end{tabular}


the composition of the formulations without acid whey to compensate for the water content in each sample. After grinding the refrigerated meat and fat separately through a $10 \mathrm{~mm}$ plate using a universal machine type KU2-3EK (MESKO-AGD, Skarzysko-Kamienna, Poland), sea salt and glucose were added and mixed. Then, either acid whey, water or freeze-dried cranberries (previously diluted in water or acid whey for better dilution) were added according to the formulations. The meat mixtures were stuffed into fibrous casings ( $\varnothing 65 \mathrm{~mm}$, VISKASE, Chicago, IL, USA).

Subsequently, the sausages were hung at $16^{\circ} \mathrm{C}$ in a drying room with a relative humidity of between $80 \%$ and $90 \%$ for 22 days. The sausages were weighed in weekly intervals and the batch was considered finished when the weight loss reached $30 \%$.

At the end of the manufacturing process (22 days), the samples were removed from the drying room and vacuum-packed in polythene pouches ( $80 \mu \mathrm{m}$ thick). The sausages were then stored in a chiller in the dark at $4^{\circ} \mathrm{C}$ for 90 days. Each sample was analyzed for $\mathrm{pH}$, water activity $\left(\mathrm{a}_{\mathrm{w}}\right)$, heme iron content, 2 -thiobarbituric acid reactive substances (TBARS) value and conjugated dienes at the end of the manufacturing process $(0$ day), and at 30 and 90 days of refrigerated storage. Fatty acid composition was measured once at the end of the manufacturing process ( 0 day).

\section{pH measurements}

To measure the $\mathrm{pH}$, a $10 \mathrm{~g}$ minced sample was homogenized with $30 \mathrm{~mL}$ de-ionized water for $1 \mathrm{~min}$ using a homogenizator (IKA ULTRA-TURRAX T25 Basic, Staufen, Germany). The $\mathrm{pH}$ was measured with a digital pH-meter CPC-501 (Elmetron, Zabrze, Poland) equipped with a pH electrode (ERH111, Hydromet, Gliwice, Poland) that had been calibrated with buffer solutions at $\mathrm{pH}$ 4.0, 7.0 and 9.0.

\section{Water activity measurements}

The water activity $\left(\mathrm{a}_{\mathrm{w}}\right)$ measurements were carried out at $20^{\circ} \mathrm{C}$ using a water activity analyzer (Novasina AG, Lachen, Switzerland), which gives temperature-controlled measurements. Novasina SAL-T humidity standards $(33 \%, 75 \%, 84 \%$, and $90 \%$ relative humidity) were used for calibration.

\section{Conjugated diene analysis}

Conjugative diene (CD) concentrations were determined using a modified method adopted from Sirinivasan et al. [16]. A minced sausage samples $(5 \mathrm{~g})$ were suspended in $50 \mathrm{~mL}$ of distilled water and homogenized for 1 min (IKA ULTRATURRAX T25 Basic, Germany). A aliquot of this suspension $(5 \mathrm{~mL})$ was mixed with $50 \mathrm{~mL}$ of extracting solution (3:1 hexane:isopropanol) for $1 \mathrm{~min}$ and centrifuged at 2,000 $\mathrm{g}$ for 5 min (MPW-350R centrifuge, MPW Med-Instruments, Poland). The absorbance of the supernatant was read at $233 \mathrm{~nm}$ using a UV-VIS spectrophotometer (Nicolet Evolution 300, Thermo Electron Corporation, Madison, WI, USA). The concentration of conjugated dienes was expressed as $\mu \mathrm{mol} / \mathrm{mg}$ sample.

\section{2-Thiobarbituric acid reactive substances analysis}

Lipid oxidation was measured by the TBARS test according to the procedure proposed by Pikul et al. [17] using perchloric acid as a solvent. Distillates were reacted with thiobarbituric acid (TBA) in boiling water and absorbance was measured at $532 \mathrm{~nm}$ using a UV-VIS spectrophotometer (Nicolet Evolution 300, Thermo Electron Corporation, USA). Malondialdehyde was used to prepare the calibration curve. Values were expressed as $\mathrm{mg}$ of malondialdehyde per kilogram of the sample.

\section{Heme iron content}

The heme iron content was determined after extraction with acidified acetone solution following the analytical conditions described by Karwowska and Dolatowski [18]. The absorbance of extract was measured at $640 \mathrm{~nm}$ in a UV-VIS spectrophotometer (Nicolet Evolution 300, Thermo Electron Corporation, USA). The total pigments were calculated as haematin using the following formula: total pigment $(\mathrm{mg} / \mathrm{kg})=\mathrm{A} 640 \times 680$. The heme iron content was calculated as follow: heme iron $(\mathrm{mg} / \mathrm{kg})=$ total pigment $(\mathrm{mg} / \mathrm{kg}) \times 8.82 / 100$.

\section{Fatty acid profile determination}

The fatty acid profile of sausage was determined by gas chromatography after conversion of the fats to fatty acid methyl esters [19]. The method of Folch et al. [20] was used for the extraction of lipids from the samples. A gas chromatograph (Varian 450-GC, Walnut Creek, CA, USA) with a split/splitless injector, a flame-ionization detector and a 30-m fused silica capillary column (Select Biodiesel for FAME, Varian, USA) (30 $\mathrm{m} \times 0.32 \mathrm{~mm} \times 0.25 \mu \mathrm{m}$ film thickness) were used. Helium was the carrier gas. Injector and detector temperature were $250^{\circ} \mathrm{C}$ and $300^{\circ} \mathrm{C}$, respectively. After injection, the column temperature was programmed to rise $200^{\circ} \mathrm{C}$ maintained for $10 \mathrm{~min}$, and subsequently increased to $240^{\circ} \mathrm{C}$ at the rate of $3^{\circ} \mathrm{C} / \mathrm{min}$ and then held at the final temperature for $4 \mathrm{~min}$. The amounts of the fatty acids were calculated from the chromatograms and from an internal standard containing methyl esters of the fatty acids.

\section{Instrumental color $\left(\mathrm{L}^{*} \mathrm{a} * \mathbf{b} *\right)$}

Samples were evaluated for instrumental color by using a spectrophotometer (Color Premiere 8200; X-Rite Inc., Grand Rapids, MI, USA) using D65 illuminant, an $8 \mathrm{~mm}$ view aperture and $10^{\circ}$ standard observer. Samples for color measurements were $5 \mathrm{~cm}$ thick and before color determination were covered with a single layer of colorless food wrap. $L^{*}, a^{*}, b^{*}$ values (lightness, redness and yellowness, respectively) and reflectance 
values between 360 and $740 \mathrm{~nm}$ were measured. Redness was defined as $R_{630} / R_{580}$ [21]. $R_{630}$ is an estimate of oxymyoglobin and $\mathrm{R}_{580}$ is an estimate of metmyoglobin.

\section{Statistical analysis}

Each type of sausage was made in triplicate. All analyses were carried out three times. The statistical analysis consisted of two-way analysis of variance (ANOVA) using the general linear model procedure of Statgraphics v. 5 (Manugistics Inc., Rockville, MD, USA). The fixed factors were the treatments (F1, F2, F3, and F4) and storage time (0, 30, or 90 days), and their interactions were examined. Data from the determined fatty acid profile was analyzed by one-way ANOVA (treatments) at the end of ripening. Any significance of differences between the samples at the same storage time and the same sample at different storage times was determined (at a significance level $\mathrm{p} \leq 0.05$ ) using Tukey's test.

\section{RESULTS AND DISCUSSION}

Table 2 shows the effects of both treatment and storage time on the physicochemical characteristics of nitrite-free fermented sausage made from deer meat that was stored in the dark at $4^{\circ} \mathrm{C}$ for up to 90 days. The results indicate that both treatment and storage time significantly affected $(\mathrm{p} \leq 0.05)$ the $\mathrm{pH}$ value, moreover, significant interactive effects were found between the fixed factors. The obtained results showed that the incorporation of acid whey and/or freeze-dried cranberries to the composition of dry-fermented sausage did not have a statistically significant effect on the $\mathrm{pH}$ at the end of ripening or on 30 and 90 days of storage. The inclusion of acid whey to the sausage together with freeze-dried cranberries significantly decreased the $\mathrm{pH}$ values on 0 and 90 days of storage. The $\mathrm{pH}$ values in formulations $\mathrm{F} 2$ and $\mathrm{F} 4$ rose significantly from day 0 to day 30 , probably due to microbial enzyme and deaminase activities producing alkaline nitrogenous substances, as report- ed by Bozkurt and Erkmen [22].

An effective reduction of $\mathrm{pH}$ in salted sausage is especially important for sausages which are ripened over a short period of time and possess comparatively high water activity. The fermented sausage we investigated here attained low $\mathrm{pH}$ during storage ( $\mathrm{pH} 4.47$ to 69 ) probably through the action of lactic acid-forming bacteria, as was already observed in venison (Dama Dama) nitrite-free dry-cured sausages [9]. At the end of ripening, all samples presented similar values for the $\mathrm{pH}$ ( $\mathrm{pH} 4.47$ to 4.59 ). These values were lower than those obtained by Soriano et al. [23] in dry sausages prepared from deer meat. This can be explained by seasonal variation in venison $\mathrm{pH}$ and by the relative activities of calpastatin-bound calpain, $\mu$-calpain and $\mathrm{m}$-calpain, as the research studies of Wiklund et al. [24] have shown. Numerous studies cited by Hughes et al. [25] have concluded that endogenous proteinases are primarily responsible for proteolysis during sausage fermentation by causing a generation of large-sized peptides which are, in turn, degraded to oligopeptides and then to free amino acids. Their deamination, decarboxylation and transamination give rise to several low molecular weight compounds, such as ammonia, ketoacids, amines, methyl ketones, and aldehydes.

The water activity of the sausage samples was affected by the storage time, and interaction of storage time and treatment was significant $(\mathrm{p} \leq 0.01)$ (Table 2$)$. The addition of acid whey a nd/or freeze-dried cranberries did not affect the product's water activity. At day 0, the fermented sausage samples presented water activity values between 0.932 and 0.936 , which were similar to those found by Park and Lee [26] for fermented sausages produced with kimchi. Their results demonstrated that the water activity values, after processing for 4 weeks, in sausage that contained $5 \%$ kimchi powder was significantly lower than that of the control. The results of the present study showed that the water activity of almost all of the samples decreased significantly from day 0 to day 30 , probably due to the breakdown of some low molecular components via enzymatic

Table 2. Physicochemical characteristics of fermented venison sausage (mean values \pm standard error of the mean)

\begin{tabular}{|c|c|c|c|c|c|c|c|c|}
\hline \multirow{2}{*}{ Items } & \multirow{2}{*}{$\begin{array}{l}\text { Storage time } \\
\qquad(\mathrm{S}, \mathrm{d})\end{array}$} & \multicolumn{4}{|c|}{ Treatment (T) } & \multicolumn{3}{|c|}{ Significance } \\
\hline & & F1 & F2 & F3 & F4 & $\mathbf{T}$ & $S$ & $\mathrm{~T} \times \mathrm{S}$ \\
\hline \multirow[t]{3}{*}{ pH } & 0 & $4.54 \pm 0.04^{\mathrm{bA}}$ & $4.59 \pm 0.03^{\mathrm{bA}}$ & $4.56 \pm 0.02^{\mathrm{bA}}$ & $4.47 \pm 0.03^{\mathrm{aA}}$ & * & * & * \\
\hline & 30 & $4.62 \pm 0.03^{\mathrm{aAB}}$ & $4.69 \pm 0.04^{\mathrm{aB}}$ & $4.59 \pm 0.08^{\mathrm{aAB}}$ & $4.66 \pm 0.03^{\mathrm{aB}}$ & & & \\
\hline & 90 & $4.68 \pm 0.04^{b B}$ & $4.66 \pm 0.02^{b B}$ & $4.67 \pm 0.03^{\mathrm{bB}}$ & $4.61 \pm 0.02^{\mathrm{aB}}$ & & & \\
\hline \multirow[t]{3}{*}{$a_{w}$} & 0 & $0.936 \pm 0.001^{B}$ & $0.933 \pm 0.008^{B}$ & $0.933 \pm 0.003^{B}$ & $0.932 \pm 0.002^{B}$ & NS & * & ** \\
\hline & 30 & $0.927 \pm 0.004^{A}$ & $0.919 \pm 0.005^{A}$ & $0.921 \pm 0.004^{A}$ & $0.925 \pm 0.006^{A B}$ & & & \\
\hline & 90 & $0.926 \pm 0.006^{A}$ & $0.925 \pm 0.004^{B}$ & $0.917 \pm 0.005^{A}$ & $0.920 \pm 0.001^{\mathrm{A}}$ & & & \\
\hline \multirow{3}{*}{$\begin{array}{r}\text { Heme iron } \\
(\mathrm{mg} / \mathrm{kg})\end{array}$} & 0 & $23.92 \pm 0.28^{\mathrm{aB}}$ & $23.50 \pm 0.37^{\mathrm{aB}}$ & $23.78 \pm 1.65^{\mathrm{aB}}$ & $23.69 \pm 1.44^{\mathrm{aB}}$ & * & * & * \\
\hline & 30 & $21.35 \pm 2.23^{\mathrm{aA}}$ & $23.92 \pm 0.76^{\mathrm{aB}}$ & $23.33 \pm 0.81^{\mathrm{aB}}$ & $21.64 \pm 1.11^{a \mathrm{~B}}$ & & & \\
\hline & 90 & $20.14 \pm 0.48^{\mathrm{bA}}$ & $19.03 \pm 1.02^{\mathrm{abA}}$ & $21.52 \pm 0.35^{\mathrm{CA}}$ & $18.10 \pm 0.21^{\mathrm{aA}}$ & & & \\
\hline
\end{tabular}

T, treatment; S, storage time; $T \times S$, treatment-storage time interaction; NS, not significant.

a-c Within the same storage time, means followed by the same lower case letters between the samples do not differ significantly.

${ }^{A-B}$ Means followed by the same capital letters between the same sample at different storage times do not differ significantly.

${ }^{*} p \leq 0.05 ;{ }^{* *} p \leq 0.01$. 
reactions [27].

Both the quality and acceptability of meat products is mainly determined by lipid and protein oxidation [28]. Salted, fermented sausages are especially susceptible to oxidation since salt has been proven to be a prooxidant in meat products. The prooxidant mechanism of $\mathrm{NaCl}$ is thought to include its ability to reduce antioxidant enzyme activities and to displace iron ions with sodium in the heme pigments providing free iron [29]. The results of the present study report that the formulations and storage time affected the heme iron content, and that the interaction of both factors was significant $(\mathrm{p} \leq 0.05)$. All samples presented similar values for the heme iron content at day 0 and day 30 (Table 2). However, the heme iron content of fermented sausage was significantly decreased on day 90 as compared to that on day 0 and 30 . The obtained results indicated that the lowest heme iron content of fermented sausage was characterized by the sample with the addition of acid whey in combination with freeze-dried cranberries. The highest content of heme iron at day 90 was found in the F3 formulation with the addition of freeze-dried cranberries. The obtained results suggest that the addition of cranberries, rich in phenolic compounds, stabilized the porphyrin ring of the heme molecule during storage and thereby reduced the release of iron. However, as is suggested by the obtained results, the redox chemistry of these compounds may be different when they are combined with acid whey. Our previous results indicated that the antioxidant activities of acid whey and mustard seed compounds stabilized the porphyrin ring of the heme molecule during model cooked sausage storage as effectively as curing salt [30].

Venison is characterized by a high content of phospholipids as well as of heme pigments and heme iron, which makes it susceptible to oxidation [3]. The occurrence of primary (conjugated dienes) and secondary products (TBARS) of fatty acid oxidation measured over 90 days of storage is shown in Table 3. The storage time and formulations affected lipid oxidation, and the interaction of both factors was significant $(\mathrm{p} \leq 0.05)$. The results of the present study showed that both the CD and TBARS values were relatively high at the beginning of the stor- age period, and this could be due to the elimination of nitrite/ nitrate, which is a typical curing agent and acts against lipid oxidation. Nitrite-free fermented sausage made from deer meat with acid whey and/or freeze-dried cranberries appeared to be less susceptible to the formation of conjugated dienes within the first 30 days of storage as compared to the control (F1) formulation. The results of the $\mathrm{CD}$ measurements reached at the beginning of the experiment and on day 30 for the F1 formulation were significantly higher than those obtained for the F2 to F4 sausage formulations. No statistical differences were observed in the concentration of $\mathrm{CD}$ among all sausage samples on day 90 . With the exception of the F1 formulation, the formation of $\mathrm{CD}$ was not affected by the time of storage.

TBARS showed a constant increase during storage, which proved that secondary products of lipid oxidation had accumulated during storage (Table 3). Measurements of TBARS values indicated that the addition of freeze-dried cranberries to the composition of fermented venison sausage had an effect on the secondary products of lipid oxidation. The F3 sausage formulation was characterized by lower TBARS values during the whole storage period as compared to the control formulation, which is important because lipid oxidation products have harmful biological effects which promote neurodegenerative and cardiovascular diseases as well as different types of cancer, but only when these products are consumed in large quantities for an extended period of time [31]. The lower lipid oxidation which was observed in products with freeze-dried cranberries (Formulation F3) was related to the amount of flavonols which act as free radical scavengers and metal chelators [15]. Numerous studies cited by Caillet et al. [32] have concluded that cranberry phenolic compounds have free radical-scavenging properties against superoxide radical $\left(\mathrm{O}_{2}\right)$, hydrogen peroxide $\left(\mathrm{H}_{2} \mathrm{O}_{2}\right)$, hydroxyl radicals $(\cdot \mathrm{OH})$, and singlet oxygen $\left({ }^{1} \mathrm{O}_{2}\right)$, and they can also inhibit lipid peroxidation. This is of particular importance in the case of venison, as research conducted by many authors [33] indicated that meat with a higher heme pigment content produces more hydrogen peroxide $\left(\mathrm{H}_{2} \mathrm{O}_{2}\right)$ during oxymyoglobin autooxidation than meat with fewer heme pigments. Hydrogen peroxide can re-

Table 3. Primary and secondary products of lipid oxidation of fermented venison sausage (mean values \pm standard error of the mean)

\begin{tabular}{|c|c|c|c|c|c|c|c|c|}
\hline \multirow{2}{*}{ Items } & \multirow{2}{*}{$\begin{array}{l}\text { Storage time } \\
\qquad(\mathrm{S}, \mathrm{d})\end{array}$} & \multicolumn{4}{|c|}{ Treatment $(\mathrm{T})$} & \multicolumn{3}{|c|}{ Significance } \\
\hline & & F1 & F2 & F3 & F4 & $T$ & $S$ & $\mathrm{~T} \times \mathrm{S}$ \\
\hline \multirow{2}{*}{$\begin{array}{l}\text { Conjugated dienes } \\
(\mu \mathrm{mol} / \mathrm{mg})\end{array}$} & 0 & $0.308 \pm 0.021^{\mathrm{bB}}$ & $0.207 \pm 0.011^{\mathrm{aA}}$ & $0.216 \pm 0.021^{\mathrm{aA}}$ & $0.226 \pm 0.059^{\mathrm{aA}}$ & ** & * & * \\
\hline & 90 & $0.227 \pm 0.019^{\mathrm{aA}}$ & $0.228 \pm 0.024^{\mathrm{aA}}$ & $0.212 \pm 0.036^{\mathrm{aA}}$ & $0.233 \pm 0.021^{\mathrm{aA}}$ & & & \\
\hline \multirow[t]{2}{*}{ TBARS (mg/kg) } & 0 & $1.88 \pm 0.15^{\mathrm{aA}}$ & $2.33 \pm 0.16^{\mathrm{bA}}$ & $1.78 \pm 0.38^{\mathrm{aA}}$ & $2.14 \pm 0.48^{\mathrm{abA}}$ & * & ** & * \\
\hline & 30 & $2.17 \pm 0.22^{\mathrm{abA}}$ & $2.39 \pm 0.09^{\mathrm{bA}}$ & $1.95 \pm 0.12^{\mathrm{aA}}$ & $3.42 \pm 0.16^{\mathrm{CB}}$ & & & \\
\hline
\end{tabular}

T, treatment; $S$, storage time; $T \times S$, treatment - storage time interaction; TBARS, 2-thiobarbituric acid reactive substances.

a-c Within the same storage time, means followed by the same lower case letters between the samples do not differ significantly.

${ }^{A-B}$ Means followed by the same capital letters between the same sample at different storage times do not differ significantly.

${ }^{*} p \leq 0.05 ;{ }^{* *} p \leq 0.01$. 
act with metmyoglobin to generate ferrylmyoglobin, which can initiate lipid oxidation [34].

There was no synergy between the freeze-dried cranberries and acid whey compounds in terms of inhibiting lipid oxidation in dry-fermented sausage. The level of secondary products of lipid oxidation obtained for the sausage formulation with acid whey (F4) in combination with freeze-dried cranberries was similar to that obtained for the control formulation (F1) as well as for formulation F2 (with acid whey addition). The results obtained here are surprising since our previous study indicated that the addition of acid whey with a combination of mustard seed to a nitrite-free fermented sausage formulation was able to protect lipids against oxidation which was comparable to nitrite during vacuum storage [35].

The selected fatty acids and the total of the saturated fatty acids (SFA), monounsaturated fatty acids (MUFA) and PUFA proportions of dry-fermented sausage significantly affected by acid whey and/or addition of freeze-dried cranberries are presented in Table 4. The results indicate that the treatment significantly affected the fatty acid profile of fermented venison sausage $(\mathrm{p} \leq 0.05)$. The fatty acid profiles were dominated by MUFAs ( $49.23 \%$ to $55.55 \%$ of total methyl esters), followed by SFAs ( $36.08 \%$ to $42.59 \%$ of total methyl esters) and, finally, by PUFAs ( $7.52 \%$ to $8.34 \%$ of total methyl esters). These results are not in agreement with those of Paleari et al. (2003) for dry sausage made from deer, as they obtained a total SFA content of $35.5 \%$ to $44.0 \%$, MUFA content of $30.3 \%$ to $45.7 \%$, and PUFA content of $16.2 \%$ to $19.6 \%$, respectively, in fat extracted from cured products of deer from farms. In the current study, the amounts of saturated acids that were found were similar; however, the MUFAs content was higher and the PUFAs content was lower. These differences probably result from the addition of pork fat to the formulation of sausage which is rich in MUFAs. This may also be attributed to differences in conditions of rearing and feeding.

Within the MUFAs, oleic acid was the most abundant, with significant differences between samples, which was followed by palmitoleic acid. The obtained results for oleic acid content were higher than those obtained by Paleari et al. [36] for dry sausage made from deer. The results indicated that fermented sausage with the addition of freeze-dried cranberries was characterized by a higher content of oleic acid as compared to the rest of the formulations. This is likely due to oxidative changes, as the F3 formulation was also characterized by lower TBARS values during storage. The obtained results suggest that the freeze-dried cranberries added to fermented sausage made from deer meat were able to protect the MUFAs against oxidation. The obtained results do not confirm any synergy between the compounds of acid whey and freeze-dried cranberries in terms of inhibiting fatty acid oxidation in fermented venison sausage.

Within the SFAs, the main fatty acid was palmitic, which differed significantly among the groups. The sausage sample

Table 4. Fatty acid profile of fermented venison sausage (\%) (mean values \pm standard error of the mean)

\begin{tabular}{|c|c|c|c|c|c|}
\hline \multirow{2}{*}{ Items } & \multicolumn{4}{|c|}{ Treatment } & \multirow{2}{*}{ Significance } \\
\hline & F1 & F2 & F3 & F4 & \\
\hline \multicolumn{6}{|c|}{ Saturated } \\
\hline 10:0 & $0.08 \pm 0.01$ & $0.09 \pm 0.01$ & $0.09 \pm 0.01$ & $0.09 \pm 0.01$ & NS \\
\hline $12: 0$ & $0.10 \pm 0.01$ & $0.10 \pm 0.01$ & $0.09 \pm 0.01$ & $0.09 \pm 0.01$ & NS \\
\hline $14: 0$ & $1.61 \pm 0.02^{\mathrm{a}}$ & $1.69 \pm 0.02^{b}$ & $1.62 \pm 0.01^{\mathrm{a}}$ & $1.67 \pm 0.01^{b}$ & * \\
\hline $15: 0$ & $0.08 \pm 0.01$ & - & - & - & - \\
\hline $16: 0$ & $26.83 \pm 0.37^{b}$ & $26.73 \pm 0.76^{b}$ & $23.96 \pm 0.28^{\mathrm{a}}$ & $25.83 \pm 0.90^{b}$ & * \\
\hline $17: 0$ & $0.18 \pm 0.01$ & $0.17 \pm 0.01$ & $0.17 \pm 0.01$ & $0.17 \pm 0.01$ & NS \\
\hline $18: 0$ & $13.52 \pm 0.16^{b}$ & $12.92 \pm 0.74^{b}$ & $10.00 \pm 0.29^{a}$ & $11.82 \pm 1.20^{\mathrm{ab}}$ & * \\
\hline $20: 0$ & $0.49 \pm 0.01^{b}$ & $0.16 \pm 0.01^{\mathrm{a}}$ & $0.16 \pm 0.04^{a}$ & $0.18 \pm 0.010^{a}$ & * \\
\hline Total & $42.59 \pm 0.21^{c}$ & $41.81 \pm 1.48^{\mathrm{bc}}$ & $36.08 \pm 0.57^{\mathrm{a}}$ & $39.73 \pm 1.96^{b}$ & * \\
\hline \multicolumn{6}{|c|}{ Monounsaturated } \\
\hline $14: 1$ & $0.08 \pm 0.02$ & - & - & - & - \\
\hline $16: 1$ & $3.86 \pm 0.08^{\mathrm{a}}$ & $4.42 \pm 0.52^{b}$ & $6.44 \pm 0.04^{c}$ & $5.04 \pm 0.93^{b}$ & * \\
\hline $18: 1$ & $44.49 \pm 0.31^{\mathrm{a}}$ & $46.11 \pm 0.76^{b}$ & $49.11 \pm 0.30^{c}$ & $46.78 \pm 1.32^{b}$ & * \\
\hline $20: 1$ & $0.81 \pm 1.00$ & - & - & - & - \\
\hline Total & $49.23 \pm 0.78^{a}$ & $50.53 \pm 1.28^{\mathrm{a}}$ & $55.55 \pm 0.25^{b}$ & $51.81 \pm 2.26^{\mathrm{a}}$ & * \\
\hline \multicolumn{6}{|c|}{ Polyunsaturated } \\
\hline $18: 2$ & $7.66 \pm 0.78$ & $7.48 \pm 0.46$ & $8.34 \pm 0.35$ & $8.30 \pm 0.45$ & NS \\
\hline $18: 3$ & $0.11 \pm 0.01^{c}$ & $0.08 \pm 0.01^{b}$ & - & $0.05 \pm 0.01^{\mathrm{a}}$ & * \\
\hline $20: 2$ & $0.10 \pm 0.03$ & - & - & - & - \\
\hline Total & $7.89 \pm 0.71$ & $7.52 \pm 0.21$ & $8.34 \pm 0.35$ & $8.32 \pm 0.28$ & NS \\
\hline
\end{tabular}

NS, not significant.

${ }^{a-c}$ Means followed by the same lower case letters between the samples do not differ significantly.

${ }^{*} p \leq 0.05$. 
with freeze-dried cranberries (F3) was characterized by the lowest content of palmitic acid. Finally, within the PUFAs, linoleic acid was predominant but did not differ significantly among the groups; followed by linolenic acid, which was highest in the F1 formulation. Although cranberries are rich in a-linolenic acid or in n-3 fatty acids [37], no effect of the addition of freeze-dried cranberries on the PUFA content was indicated in fermented venison sausage.

Color, especially redness $\left(\mathrm{a}^{*}\right)$ is the most important characteristic of nitrite-free meat product. Statistical analysis displayed that color coordinates $\left(L^{*}, a^{*}, b^{*}\right)$ were significantly influenced by treatment $(p \leq 0.05)$ and storage time $(p \leq 0.05)$ (Table 5$)$. In relation to $\mathrm{L}^{*}$ values, on day 0 , the fermented sausage samples with acid whey (F2), freeze-dried cranberries (F3), and acid whey in combination with freeze-dried cranberries (F4) presented the significantly higher lightness compared to controls. It could be due to the fermentation process which creates the acid compounds of increased lightness in sausage samples. The time of storage did not change $\mathrm{L}^{*}$ values in F2, F3, and F4 samples. This could indicates that acid whey, freeze-dried cranberries and acid whey in combination with freeze-dried cranberries were successful at reducing the bowing reaction involved in the formation of dark color in fermented sausage. Application of acid whey and freeze-dried cranberries resulted in significantly lower $\mathrm{a}^{*}$ values and ratios $630 / 580 \mathrm{~nm}$ (redness) in F2, F3, and F4 samples than in samples with sea salt only. This is not in agreement with previous results by Wójciak et al. [30], who hypothesized that $\beta$-lactoglobulin which is acid whey protein could serve as a source of thiol amino acids and glutathione and demonstrate antioxidant activity. Their reduced forms remove free radical and protect meat products against discoloration.

\section{CONCLUSION}

The use of freeze-dried cranberries positively affected oxidative processes of nitrite-free fermented sausages made from deer meat. The application of freeze-dried cranberries can lower the intensity of oxidative changes during the storage of fermented sausage without nitrite. The results obtained here suggest that the addition of freeze-dried cranberries, which are rich in phenolic compounds, stabilized the porphyrin ring of the heme molecule during storage and thereby reduced the release of iron. In sausages with freeze-dried cranberries, the sum of unsaturated fatty acids was higher as compared to the control sausage. In addition, conjugated dienes and TBARS had a lower content in these samples during storage. The use of a combination of freeze-dried cranberries and acid whey was not effective in inhibiting lipid oxidation in dry-fermented venison sausage without nitrite. Therefore, it is of interest to proceed with research dealing with the use of freeze-dried cranberries in a nitrite-free fermented sausage formulation made from deer meat to improve the quality of these kinds of products for human consumption. However, further research is needed to assess the applicability of such nitrite-free technology.

\section{CONFLICT OF INTEREST}

We certify that there is no conflict of interest with any financial organization regarding the material discussed in the manuscript.

\section{ACKNOWLEDGMENTS}

The research presented in this paper was supported by a Ministry of Agriculture and Rural Development project, nr PKre029-4-3/12(608).

Table 5. Color coordinate of fermented venison sausage (mean values \pm standard error of the mean)

\begin{tabular}{|c|c|c|c|c|c|c|c|c|}
\hline \multirow{2}{*}{ Items } & \multirow{2}{*}{$\begin{array}{l}\text { Storage } \\
\text { time }(S, d)\end{array}$} & \multicolumn{4}{|c|}{ Treatment $(\mathrm{T})$} & \multicolumn{3}{|c|}{ Significance } \\
\hline & & $\mathrm{F} 1$ & $\mathrm{~F} 2$ & F3 & $\mathrm{F} 4$ & $T$ & $S$ & $\mathrm{~T} \times \mathrm{S}$ \\
\hline \multirow[t]{3}{*}{$L^{*}$} & 0 & $46.51 \pm 1.98^{\mathrm{aA}}$ & $53.13 \pm 2.40^{\mathrm{bA}}$ & $49.80 \pm 2.04^{\mathrm{bA}}$ & $58.49 \pm 4.09^{\mathrm{CA}}$ & * & * & * \\
\hline & 30 & $40.34 \pm 1.92^{\mathrm{aB}}$ & $52.70 \pm 3.05^{\mathrm{bA}}$ & $49.28 \pm 2.06^{\mathrm{bA}}$ & $54.93 \pm 1.22^{\mathrm{bA}}$ & & & \\
\hline & 90 & $41.97 \pm 1.76^{\mathrm{aB}}$ & $56.69 \pm 3.63^{\mathrm{bA}}$ & $51.92 \pm 4.04^{\mathrm{bA}}$ & $56.01 \pm 3.65^{\mathrm{bA}}$ & & & \\
\hline \multirow[t]{3}{*}{$a^{*}$} & 0 & $3.07 \pm 0.15^{\mathrm{bB}}$ & $2.61 \pm 0.34^{\mathrm{aA}}$ & $3.11 \pm 0.17^{\mathrm{bA}}$ & $2.19 \pm 0.95^{\mathrm{aA}}$ & * & * & ** \\
\hline & 30 & $3.01 \pm 0.19^{\mathrm{bB}}$ & $3.27 \pm 0.44^{\mathrm{bB}}$ & $3.15 \pm 0.48^{\mathrm{bA}}$ & $2.38 \pm 0.21^{\mathrm{aA}}$ & & & \\
\hline & 90 & $2.52 \pm 0.20^{\mathrm{aA}}$ & $2.22 \pm 0.32^{\mathrm{aA}}$ & $2.79 \pm 0.45^{\mathrm{aA}}$ & $2.61 \pm 0.18^{\mathrm{aA}}$ & & & \\
\hline \multirow[t]{3}{*}{$b^{*}$} & 0 & $7.54 \pm 0.33^{\mathrm{aA}}$ & $7.68 \pm 0.53^{\mathrm{aA}}$ & $6.41 \pm 0.34^{\mathrm{AA}}$ & $6.69 \pm 0.40^{\mathrm{aA}}$ & * & * & * \\
\hline & 30 & $10.02 \pm 0.34^{C B}$ & $8.87 \pm 0.24^{\mathrm{bB}}$ & $7.56 \pm 1.01^{\mathrm{AA}}$ & $7.26 \pm 0.45^{\mathrm{aB}}$ & & & \\
\hline & 90 & $7.89 \pm 0.11^{\mathrm{aA}}$ & $7.40 \pm 0.19^{\mathrm{aA}}$ & $7.08 \pm 0.31^{\mathrm{aA}}$ & $9.31 \pm 0.10^{\mathrm{bc}}$ & & & \\
\hline \multirow[t]{3}{*}{ Redness $630 / 580 \mathrm{~nm}$} & 0 & $1.36 \pm 0.03^{\mathrm{bA}}$ & $1.23 \pm 0.03^{\mathrm{aA}}$ & $1.32 \pm 0.08^{\mathrm{bA}}$ & $1.26 \pm 0.06^{\mathrm{aA}}$ & * & * & * \\
\hline & 30 & $1.39 \pm 0.06^{\mathrm{aA}}$ & $1.36 \pm 0.09^{\mathrm{aB}}$ & $1.37 \pm 0.02^{2 \mathrm{~A}}$ & $1.34 \pm 0.01^{\mathrm{aB}}$ & & & \\
\hline & 90 & $1.31 \pm 0.03^{\mathrm{bA}}$ & $1.24 \pm 0.04^{\mathrm{aA}}$ & $1.33 \pm 0.56^{b A}$ & $1.23 \pm 0.01^{\mathrm{aA}}$ & & & \\
\hline
\end{tabular}

NS, not significant.

a-c Within the same storage time, means followed by the same lower case letters between the samples do not differ significantly.

${ }^{A-B}$ Means followed by the same capital letters between the same sample at different storage times do not differ significantly.

${ }^{*} p \leq 0.05 ;{ }^{* *} p \leq 0.01$. 


\section{REFERENCES}

1.Ramanzin M, Amici A, Casoli C, et al. Meat from wild ungulates: ensuring quality and hygiene of an increasing resource. Ital J Anim Sci 2010;9:e61.

2.Daszkiewicz T, Hnatyk N, Dąbrowski D, et al. A comparison of the quality of the Longissimus lumborum muscle from Wild and farm-raised fallow deer (Dama dama L.). Small Rum Res 2015; 129:77-83.

3.Okabe Y, Watanabe A, Shingu $\mathrm{H}$, et al. Effects of $\alpha$-tocopherol level in raw venison on lipid oxidation and volatiles during storage. Meat Sci 2002;62:457-62.

4.Daszkiewicz T, Janiszewski P, Wajda S. Quality characteristics of meat from wild red deer (Cervus Elephus L.) hinds and stags. J Muscle Foods 2009;20:428-48.

5.Quaresma MA, Trigo-Rodrigues GI, Alves SP, et al. Nutritional evaluation of the lipid fraction of Iberian red deer (Cervus elaphus hispanicus) tenderloin. Meat Sci 2012;92:519-24.

6.Ruiz-Capillas C, Tahmouzi S, Triki M, et al. Nitrite-free Asian hot dog sausages reformulated with nitrite replacers. J Food Sci Technol 2015;52:4333-41.

7.Weiss J, Gibis M, Schuh V, Salminen H. Advances in ingredient and processing systems for meat and meat products. Meat Sci 2010;86:196-213.

8.Żochowska-Kujawska J, Lachowicz K, Sobczak M. Effects of fibre type and kefir, wine lemon, and pineapple marinades on texture and sensory properties of wild boar and deer longissimus muscle. Meat Sci 2012;92:675-80.

9.Cenci-Goga BT, Rossitto PV, Sechi P, et al. Effect of selected dairy starter cultures on microbiological, chemical and sensory characteristics of swine and venison (Dama dama) nitrite-free dry-cured sausages. Meat Sci 2012;90:599-606.

10. Aro AJM, Nyam-Osor P, Tsuji K, et al. The effect of starter culture on proteolitic changes and amino acid content in fermented sausage. Food Chem 2010;119:279-85.

11. Vuorela S, Salminen H, M. Makela, et al. 2005. Effect of plant phenolics on protein and lipid oxidation in cooked pork meat patties. J Agric Food Chem 53:8492-97.

12. Lee CH, Reed JD, Richards MP. Ability of various polyphenolic classes from cranberry to inhibit lipid oxidation in mechanically separated turkey and cooked ground pork. J Muscle Foods 2006; 17:248-66.

13. Kathirvel P, Gong Y, Richards MP. Identification of the compound in a potent cranberry juice extract that inhibits lipid oxidation in comminuted muscle. Food Chem 2009;115:924-32.

14. Tong LM, Sasaki S, McClements DJ, Decker EA. Mechanisms of the antioxidant activity of a high molecular weight fraction of whey. J Agric Food Chem 2000;48:1473-8.

15. Grace MH, Massey AR, Mbeunkui F, Yousef GG, Lila MA. Comparison of health-relevant flavonoids in commonly consumed cranberry products. J Food Sci 2012;77:H176-H83.

16. Sirinivasan S, Xing YL, Decker A. Inhibition of protein and lipid oxidation in beef heart surimi-like material by antioxidants and combination of $\mathrm{pH}, \mathrm{NaCl}$, and buffer type in the washing media. J Agric Food Chem 1996;44:119-25.

17. Pikul J, Leszczyński DE, Kummerow FA. Evaluation of three modified TBA methods for measuring lipid oxidation in chicken meat. J Agric Food Chem 1989;37:1309-15.

18. Karwowska M, Dolatowski ZJ. Comparison of lipid and protein oxidation, total iron content and fatty acid profile of conventional and organic pork. Int J Food Sci Technol 2013;48:2200-6.

19. AOAC (Association of Official Analytical Chemists) International. AOAC Official Methods 969.33. Fatty acids in oils and fats. AOAC-IUPAC Method, MD: AOAC International, 1990.

20. Folch J, Lees M, Sloane-Stanley GH. A simple method for the isolation and purification of total lipids from animal tissues. J Biol Chem 1957;226:497-509.

21. AMSA (American Meat Science Association). Guidelines, instrumental meat color measurement In: Meat Color Measurements Guidelines. Champaign, IL: American Meat Science Association; 2012. pp. 45-52.

22. Bozkurt H, Erkmen O. Effects of some commercial additives on the quality sucuk (Turkish dry-fermented sausage). Food Chem 2007;101:1465-73.

23. Soriano A, Cruz B, Gómez L, Mariscal C, García Ruiz A. Proteolysis, physicochemical characteristics and free fatty acid composition of dry sausages made with deer (Cervus elaphus) or wild boar (Sus scrofa) meat: A preliminary study. Food Chem 2006; 96:173-84.

24. Wiklund E, Dobbie P, Stuart A, Littlejohn RP. Seasonal variation in red deer (Cervus elaphus) venison (M. longissimus dorsi) drip loss, calpain activity, colour and tenderness. Meat Sci 2010;86: 720-7.

25. Hughes MC, Kerry JP, Arendt EK, Kenneally PM, McSweeney $\mathrm{PLH}$, O'Neill EE. Characterization of proteolysis during the ripening of semi-dry fermented sausages. Meat Sci 2002;62:205-16.

26. Park Y-S, Lee J-Y. The effect of kimchi on the microbiological stability of fermented sausage. Meat Sci 2012;92:721-7.

27. Martín-Sánchez AM, Chaves-López C, Sendra E, et al. Lipolysis, proteolysis and sensory characteristics of a Spanish fermented dry-cured meat product (salchichón) with oregano essential oil used as surface mold inhibitor. Meat Sci 2011;89:35-44.

28. Falowo AB, Fayemi PO, Muchenje V. Natural antioxidants against lipid-protein oxidative deterioration in meat and meat products: a review. Food Res Int 2014;64:171-81.

29. Li C, Xiong YL, Chen J. Protein oxidation at different salt concentrations affects the cross-linking and gelation of pork myofibrillar protein catalysed by microbial transglutaminase. J Food Sci 2013; 78:C823-C31.

30. Wójciak KM, Karwowska M, Dolatowski ZJ. Use of acid whey and mustard seed to replace nitrites during cooked sausage production. Meat Sci 2014;96:750-6.

31. Bou R, Codony R, Tres A, Decker EA, Guardiola F. Dietary strategies to improve nutritional value, oxidative stability, and sensory 
properties of poultry products. Crit Rev Food Sci Nutr 2009;49: 800-22.

32. Caillet S, Côté J, Doyon G, Sylvain JF, Lacroix M. Antioxidant and antiradical properties of cranberry juice and extracts. Food Res Int 2011;44:1408-13.

33. Min B, Nam KC, Cordray J, Ahn DU. Endogenous factors affecting oxidative stability of beef loin, pork loin, and chicken breast and thigh meats. J Food Sci 2008;73:C439-C46.

34. Baron CP, Andersen HJ. Myoglobin-induced lipid oxidation: a review. J Agric Food Chem 2002;50:3887-97.

35. Karwowska M, Wójciak KM, Dolatowski ZJ. The influence of acid whey and mustard seed on lipid oxidation of organic fermented sausage without nitrite. J Sci Food Agric 2015;95:628-34.

36. Paleari MA, Moretti VM, Beretta G, Mentasti T, Bersani C. Cured products from different animal species. Meat Sci 2003;63:485-9.

37. Parker TD, Adams DA, Zhou K, Harris M, Yu L. Fatty acid composition and oxidative stability of cold-pressed edible seed oils. J Food Sci 2003;68:1240-3. 